\title{
TRACING SOCIAL INFLUENCE IN RESPONSES TO STRATEGY CHANGE IN AN ONLINE COMMUNITY
}

\begin{abstract}
Interest into the effects of social influence on members of online communities is growing but there is a lack of knowledge about the impact of influential members in online communities on responses to strategy change. We explore social influence in responses to strategy change through content analysis of forum posts before and after a change in strategy. After a change in strategy, individual factors moderate the relationship between participation behaviour and further positive and negative behavioural responses. The details of these behavioural responses to a change in strategy are tabulated and included in a conceptual model to inform decision makers. Strategy change precipitates a reduction in social influence effects. Non-acceptance of strategy change is associated with competitor advertisement, inflammatory behaviour, offensive behaviour and complaints. This negative behaviour by small numbers of influential individuals has important ramifications for acceptance of strategy change within online communities and impacts on the viability of setting up online forums.
\end{abstract}

\section{Keywords}

Social influence, online communities, market research, internet forums, social networks, content analysis. 


\section{Introduction}

Firms are increasingly setting up online forums to communicate news to their stakeholders and create new topics to incite community engagement. Forums are becoming progressively more important because firms’ stakeholders are spending more time online (Kim, Choi, Qualls \& Han, 2008; Wang \& Lin, 2011; Xun \& Reynolds, 2010). Consequently, research into online communities is increasing across several academic disciplines (Haffaker, 2010).

In the marketing domain much of the increase in research is directed at understanding the role of online communities in altering consumers' perceptions of products and brands (Brown, Broderick \& Lee, 2007; Kozinets, 2002; Lee, Shi, Cheung, Lim, \& Sia, 2011; Sridhar \& Srinivasan, 2012; Spaulding, 2010;) and their help in forming positive relationships between the firm and its customers (Dellarocas, 2003; Dholakia, Bagozzi \& Pearo, 2004). For example, consumers now regularly view recommendations from numerous anonymous people on Amazon and trust their views over individual experts, who they may suspect have vested interest such as being paid endorsers of products. In short, new technologies such as Web 2.0 (Click \& Petit, 2010) have increased the sphere of influence for consumers and other stakeholder groups (Dellarocas, 2004; de Valck, van Bruggen \& Wierenga, 2009; Kane, Fichman, Gallaugher \& Glaser, 2009). Research findings also suggest that understanding electronic word of mouth communication within online communities is critical to firms’ branding activities (Huang, Cai, Tsang \& Zhou, 2011; Kozinets, de Valck, Wojnicki, \& Wilner, 2010; Sridhar \& Srinivasan, 2012). Such research has highlighted the advantages of setting up online forums for increasing engagement and gaining knowledge of consumers by analysing data presented online.

While there are considerable advantages for managers in setting up new online forums, such as gaining more knowledge, there is also considerable risk due to the possibility of losing some control by encouraging community interaction. An increased lack of management control over 
responses to strategy is becoming increasingly important as the number of social networks increase. Members of online communities form connections (Walther, 1996), exhibit congruent interests (Laing, Keeling \& Newholm, 2011), build trust, friendship and alliances (Dellarocas, 2003; Kozinets et al, 2010) and have reciprocity of information (Whittaker, Isaacs \& O'Day, 1997). As communities are no longer determined by actual proximity but influenced through online networks by social and group interaction (Hamman, 1999; Preece, Maloney-Krichmar \& Abras, 2003) any negative response to a firm’s strategy can be particularly damaging because they can be picked up by large numbers of others so increasing the negative impact.

When investigating online communities researchers have explored a variety of topics such as its history and emergence (Preece et al., 2003), online trust (Ba, 2001), communities of practice (Johnson, 2001) and information exchange (Burnett, 2000). However, despite a recent growth in research activity, knowledge of social influence in the context of online communities is at an early stage of development (Haffaker, 2010) and there is a need to explore social influence more fully in marketing (Kokich, 2009). In marketing the current main research focus on consumers is helping managers to understand their external stakeholders much better but there is also a need to understand social influence when operating within other stakeholder groups. In particular managers would be interested to gain more knowledge of social influence and its effects on positive and negative responses by other stakeholder groups to strategies implemented by their firms. Current research confirms that social influence does impact on participation intentions and behaviour in online forums (e.g. Zhou, 2011). However, we know little of its effects on other types of behavioural outcomes such as responses to strategies. Managers may not know about negative responses to the strategies they implement until it is too late but analysing communication in online forums may help predict the responses so managers can take remedial action. 
Prior research has neglected to trace responses to strategy change within online communities so that we know little of how social influence is used when non-customer stakeholders respond to a firm's strategies. Successful online communities can act as significant value drivers for firms (Kozinets, 1999; Spaulding, 2010) but research into the impact of social influence on responses to strategies is lacking. Of particular interest to managers and scholars alike is how small numbers of individuals operating in online forums can influence others within a social network and thus determine the response to strategies within a larger community. We investigate this important issue and report our findings in this article. Our main aim is to develop a conceptual model to show how social influence impacts on an online community's responses to strategy change.

Case study method is used to investigate the responses to a new payment strategy in a recently set-up online forum. The forum is used by the firm to communicate with its freelance workforce acting as stakeholders to produce services to its clients. We analyse posts in this online community to develop knowledge of the risks for managers when setting up online forums and to investigate the effects of social influence on responses to a strategy change implemented by the firm.

In the remainder of the article we first present the theoretical background to social influence and discuss current conceptual models and their limitations for understanding responses to strategies within online communities. We then outline our methodology and next present our data analysis and findings. We develop a conceptual model from our findings which outlines the impact of social influence on responses to strategy within an online forum. Finally, we provide explanations for our findings and draw conclusions where we discuss the implications. 


\section{Theoretical background}

Social influence refers to the process whereby "a person changes his (her) behaviour as a result of induction by another person or group (the influencing agent)” (Kelman, 1974, p. 128). It has an adaptive and bidirectional nature so social influence can be exerted by an opinion leader on opinion seekers (Flynn, Goldsmith \& Eastman, 1996), as well as being exerted on the opinion leader him (her) self (Sridhar \& Srinivasan, 2012).

Social influence can have powerful effect in online communities. For instance, research has shown to that authors' of online product reviews are influenced by their desire to appear more knowledgeable in front of the online community. Authors of comments were found to decreased their online product ratings pre-supposing that posts displaying negative opinions would be viewed as being from more knowledgeable authors (Amabile, 1983; Schlosser, 2005).

\section{Social influence theory}

Social Influence Theory (see Kelman, 1958; 1961; 1974) is characterised by three constituents: identification, internalisation and compliance (Kelman, 1961). These are sometimes referred to as social identity, group norm and subjective norm, respectively (e.g. Zhou, 2011). However, subjective norm is not included in this current study due to previously non-significant correlations to participation behaviour in social networks (Dholakia et al., 2004; Shen, Cheung, Lee \& Chen, 2011; Zhou, 2011).

\section{Social identity (or identification)}

Social identity highlights a “conception of one's self in terms of the group's defining features” (Dholakia et al., 2004, p. 244). This means that an individual will participate in an online community to further themselves, while also developing their role within the group. Researchers have further divided the concept into three major areas: cognitive, affective and evaluative 
information (Christian, Bagozzi, Abrams \& Rosenthal, 2012; Ellemers, Kortekaas \& Ouwerkerk, 1999). Social identity may increase in strength when members have endured a long series of interactions or overall membership within an online community (Zhou, 2011). Likewise, members may recognise the differences between new and experienced users. This concept shares many important ties to referent power, whereby individuals are influenced by someone they admire or identify with (Raven, 1993). Many experienced members who rely on such referent power will inhibit strong emotional ties and support to the community (Zhou, 2011). Thus, members who interact daily within online forums will feel social identity more pertinently than others. The significance of social identity in understanding social influence has been consistently supported by extant research (Bagozzi \& Dholakia, 2002; Postmes, Spears, Lee \& Novak, 2005) but we know little of its effects on responses to strategy change.

\section{Group norm (or internalisation)}

Group norm refers to acceptance by members as they interact through a congruence of mutual interests and opinions (Dholakia et al., 2004). Community members may internalise a payment strategy by a firm, for example, if they think it is fair. Previous findings suggest that group norm will occur frequently within any community (Bagozzi \& Dholakia, 2002; Kelman, 1958) and salient information provides members with congruent goals, thereby influencing conformity (Flynn \& Chatman, 2003). Critically, group norms are significant even when there are no visual cues (i.e. profile pictures) indicating that members interact due to group presence rather than visual homogeneity (Postmes, Spears \& Lea, 2000). This is crucial because some members of communities like to remain visually anonymous even though they often have the opportunity to post a profile picture. Again, prior research has highlighted that group norm will influence 
behaviour such as participation behaviour in online forums but we know little of its effects on other behaviour such as responses to strategy implemented by firms.

We therefore investigated whether there is evidence for group norm and social identity within the community and explore the impact on responses to strategy change. Drawing on the Social Influence Theory (Kelman, 1958), we investigated the importance of group conduct, 'weintentions' and congruence of opinion; suggesting members are akin to exhibiting majority influence (Bagozzi \& Dholakia, 2002; Haffaker, 2010). Consequently, if group behaviour is as significant as previous findings suggest, then members' perceptions of the company will be influenced by the community (Kozinets, 2002). Understanding this issue may help managers deal with negative communication within online forums. Such influence can cause detrimental responses to firm strategies suggesting that setting up online communities should not just be considered a minor communication tool but one that is key to the firm.

\section{Current conceptual models}

Earlier work by Bagozzi \& Dholakia (2002) revised the model of goal-directed behaviour (which only considers subjective norms) to also include group norm and social identity. Building on this work Zhou (2011) recently tested a model of social influence which posits that group norm, subjective norm and social identity lead to participation intention and participation behaviour online. Additionally, Zhou (2011) tested if group norm strongly influences social identity. Shen et al. (2011) tested the same constituents as Zhou (2011) but also included experience and 'weintentions', based on the belief-desire-intention model. Overall, current conceptual models indicate that group norm, social identity, experience and 'we-intentions' influences online community participation behaviour. 
However, current conceptual models largely focus on why participation in online communities occurs. Little is known, in contrast, on how social influence is linked to different types of behaviour and how participation online can change in response to the implementation of a strategy change. After all, with more and more companies choosing to engage in online community activity, it is crucial to know how members respond in different ways to strategy change. Essentially our aim is to investigate the effects of social influence after participation behaviour has already occurred. In doing so, we aim to develop theory to account for different types of online behaviour, in addition to participant behaviour, such as the positive and negative responses to strategy change.

\section{Methodology}

To explore the impact of social influence on responses to strategy change within online communities we use single case-study methodology. Case-study method is popular in a number of social research fields (Lee \& Lings, 2008) and is preferred when the researcher seeks to understand complex social phenomena (Yin, 2003). The rational for choosing this methodology lies in the fact that the study seeks to answer the 'how' and 'why' questions in relation to social influence and its effects on members. A longitudinal single case study has been recommended for empirical research into online communities (Kim et al., 2008) and was chosen to help reduce the interference of contextual variables and provide data on pre and post change to strategy.

Case-study method also contributed to an unobtrusive and natural process of observation of existing forum posts which reduced bias and increased validity (Mitchell \& Jolley, 2007). Our approach was to use naturalistic observation particularly suited to the study of online communities and social influence as the approach complements the complicated behaviour of the community (Kozinets, 2002). 
Researchers have proposed that social influence is inherently unconscious (Forgas \& Williams, 2001; Cialdini \& Goldstein, 2004; Nolan Schultz, Cialdini, Goldstein \& Griskenvicius, 2008; Obholzer \& Roberts, 1994) thus suggesting that it is difficult to investigate in detail by the use of questionnaires. Furthermore, sarcasm plays a significant role within many online relationships so omitting such data may lead to misinterpreting findings (Kreuz \& Caucci, 2007). Therefore, we did not rely on computer based analysis packages such as UCINET or Linguistic Inquiry and Word Count (LIWC) that have been used previously to identify network attributes and language patterns, respectively (see, for example, Haffaker, 2010). Although these programmes are effective in highlighting quantitative trends, they lack the capacity to decipher elaborate, humanistic interactions such as sarcasm (Kreuz \& Caucci, 2007) or figurative language (Feldman \& Lu, 2007).

\section{The Case Study}

Marketing Research Surveys plc. (M.R.S. anonymised) is a large marketing research organisation involved with supplying shopping panel data to clients based on regular electronic questionnaires accessed through their website by approximately 130,000 freelance workers. Prior to the research conducted here the firm set up an online forum on its website, which as a recent initiative, was used by only a small proportion of its workers. This context is particularly suited to understanding the social influence effects that are likely to be encountered by managers when setting up new online forums. Another advantage is that due to its very large size there is much more scope for studying a range of positive and negative responses to strategy change.

The change in strategy was initiated when M.R.S. were struggling to compete with other firms in the industry because they were paying the highest rewards to complete online surveys. Therefore, the company decided to lower financial rewards to its freelance workers to achieve 
the following. One, to benefit their clients by charging less for surveys. Two, to benefit members through receiving higher numbers of surveys but of course this was partially off-set by receiving less money for each survey completed. Three, to remain profitable within an increasingly competitive market place (mainly recessionary problems). All members were informed of the change in payment through the monthly newsletter; it stated the following:

\section{INSERT EXHIBIT 1 NEAR HERE}

\section{Data collection}

Every M.R.S. forum post was recorded over a three month period. This consisted of a 6-week analysis prior to the new payment strategy change and a 6-week analysis following strategy change. This ensured social influence could be explored in a period of 'normal' activity in comparison to the post strategy change period. Due to the fact that several online threads were used simultaneously, the raw data was accumulated daily so that no posts would be overlooked. By gathering the information in this way we were able to more accurately estimate the most frequently posted subjects, so that a coding-frame could be produced.

\section{Ethical Issues}

The research abided by confidentiality guidelines (see American Psychological Association, 2002; Eysenbach \& Till, 2001). Individuals were anonymised and unique identifiers such as email addresses, dates or times of forum posts removed. Members remain strictly anonymous.

\section{Coding}

Forum posts were analysed and classified into the coding-frame by subject matter and whether the post was inferring either a positive, negative or neutral opinion of M.R.S. plc. 
All posts were then anonymised. To enhance reliability, the procedure integrated deviant case analysis; utilising both supporting and opposing evidence to assess completeness. This critical step provided deeper insights into the market research community. Three coders were used in order to increase validity. After data entry was completed any discrepancies were discussed and subsequently resolved as a group. All topics that were assigned to two posts or less were included in the 'Other' category, in order to highlight only the most significant topics.

Prior online community research has predominantly relied on questionnaires to measure social influence so an alternative approach was required to assess the two constituents of social influence in our direct qualitative research on the forum posts. The two components of social influence (social identity and group norm) where investigated as follows:

Social identity is the sense of identity that is felt within the community. Changes in belongingness and identification with M.R.S. were assessed by whether members criticised the company or recommended or praised their competitors. Group norm refers to the influence that is drawn from the congruence of opinions or values (Shen et al., 2011). There were specific forums on the M.R.S. website that were used for workers to comment on their personal interests and opinions. High group norm should be evident by many people commenting on these posts. Increases or decreases in the number of comments were used to reflect changes in the congruence of opinions.

\section{Findings}

Analysis of the online community posts suggest that social influence constituents acted as dominant antecedents to participation in the forum and further behaviour online before and after the change in payment strategy. 


\section{Antecedents to online behavioural responses to strategy change}

Both Social identity and Group norm effects were found to be significant in the forum.

Social identity

Social identity was a key feature within several forum posts published; as such, members of

M.R.S. identified with and endeavoured to defend other members when they were attacked in the online forum. This supports the findings from previous social influence research (Bagozzi \& Dholakia, 2002; Zhou, 2011). For instance:

\section{RE: Confidentiality on Surveys}

"I have recently noticed that more and more survey sites are now asking for our Postcodes as one of their demographic questions during a survey. To me, this is getting very close to a breach in confidentiality. I live in a very rural area, and only three houses share the same postcode. The Survey sites give no explanation as to why they suddenly require this information. Surely the general area of, where we live, is sufficient?" (Linda)

"Well you don't have to give your postcode if you don't want to. I mean I fail to see what possible harm giving your post code can cause and if you go to the Royal Mail site, it's possible to discover the post code of anywhere in the country - perhaps you didn't know that. The "general" area is not good enough for some clients such as supermarkets who would want to know the opinions of folk within about 5 to 10 miles of their branches, perhaps this did not occur to you. Just in case you are wondering, I don't work for M.R.S. plc but I do use my brains." (Richard)

"I think your comments aimed at Linda are really quite offensive and inappropriate. I myself have wondered (and there has been a similar recent thread on here) why all of a postcode is required as giving a postcode can dramatically narrow down the area of the person being surveyed to the 10 or so houses that each postcode covers in a street. Survey answers are meant to be confidential so the first part of a postcode is sufficient but most survey sites (inc. M.R.S. plc) do not allow you to do this. Why? This would definitely give the opinions of people in the 5-10 mile radius that you "used to brains" to mention. Please let's all be a bit more civil on these forums and consider that if you developed memory loss or alzheimers in the future then your "brains" may not work as well as they appear to do now." (Elaine) 
The member (Elaine) who attempts to enforce the 'rules' of the M.R.S. forums and defends a fellow member is one of the most frequent authors within the community. She shares strong emotional ties with the company and has developed a personal, social identity within the M.R.S. online group; such qualities closely reflect 'we-intentions' and such members consider themselves an inherent part of the community and important opinion leaders (Bagozzi \& Dholakia, 2002). Such loyalty was evident in many members that regularly create new threads, however due to a lack of experience (the forum was recently introduced) it was not a common theme within this particular community.

\section{Group norm}

Group norm was significant within M.R.S.'s online community with many members created and commented on posts due to congruent interests and opinions. This resonates with previous findings (e.g. Dholakia et al., 2004; Zhou, 2011).

$\underline{\mathrm{RE}: \mathrm{IPad}}$

"Like everyone else that enjoys new technology ( even if I am a technophobe) I am looking forward to getting my hands on an I Pad although I will be waiting till the price has dropped considerably. It may be that Apple are steaming ahead of microsoft with products like these, they can't compete with the value for money that Microsoft products give. Maybe all of us that want to try the new I Pad should set up some kind of product testing forum..... Well a girl can dream can't she :S.” (Tracey)

“I like gadgets-- but have you seen the price!!!” (Vicky)

"I agree with you vicky, far too expensive for a toy." (Irene)

“Doesn't stop me entering all the competitions I can find to win one though!” (Vicky)

"Personally struggle to see the point of one...cannot get my head around how one goes about typing on it without craning your neck over your lap or a table, as its flat...and yes I have seen the selection of extra gizmo's on the apple website that may make this possible, by then why do we need to pay for them as an extra if they are necessary for 
something as simply as typing! cant get my head around the appeal...plus very expensive for what it essentially it... a large iphone!” (Roisin)

"I dont see the point either, i like to read my books and be able to turn the pages with my fingers not stick fingers on a screen, $i$ think they are the iphone but supposedly bigger and better, $i$ have seen how big they are and $i$ think its a bit stupid really, id rather the traditional books etc and laptop how they get used now, not something without a lid or any type of protection, imagine falling over with that thing, it would break instantly and then youd be gutted unless your rich and have no sense.

I like gadgets dont get me wrong i got a 52inch tv last year, blue ray player, upscalingdvd player etc but theres no way $i$ would get an ipad and at 23 im "supposed" to want these computory things" (Glenys)

Such influence was evident even though members of the community are heterogeneous and were visually anonymous (as the thread contained no profile pictures); again, comparable to previous findings (Postmes et al., 2000). There was considerable evidence of imitation of opinion which suggests that negative comments will also influence attitudes towards the firm (Kozinets, 2002; Spaulding, 2010). The most succinct and interesting example is shown next, which goes some way in illustrating the strength and coverage of social influence. Here one member, who was wrongly concerned that surveys have slowed down nearing the 50 points (where payment is imminent), has influenced three new threads and eleven new posts. Flow Diagram 1 highlights how even a fictitious change of strategy can influence other members within an online community. Individuals chose not only to accept the opinion of another member but also to create new threads to further increase influence. This can be seen in Flow Diagram 1 where Mervyn created two threads and Clare created one thread after they had commented on previous posts:

INSERT FLOW DIAGRAM 1 NEAR HERE 
Following the change in payment strategy there was evidence to suggest that group norm decreased. Before the strategy change there was 103 posts produced on members interests, this was the highest coded topic within a 6 week timeframe (Table 1). Yet this did not continue as much following the strategy change where this number plummeted to just 28 posts. Thus, after the change in payment, members related to each other much less. This is surprising as it would be logical to assume that a controversial change in payment strategy would lead to more interaction between members and less between members and forum moderators (staff managing the forum). This was not the case as members commented much less on their own posts, whereas there was less difference between the posts that M.R.S. forum moderators created (91 before, 72 after strategy change). Overall, group norm was an evident feature within the M.R.S. community.

\section{INSERT TABLE 1 NEAR HERE}

\section{Moderating variables}

Unlike previous research, online behaviour was not just initiated by others within the community but acceptance and non-acceptance of strategy change and subsequent online behaviour was dependent on individual factors linked to monetary reward. For example:

\section{$\underline{R E \text { : surveys }}$}

"It has taken me just about a year and i am $£ 4.50$ short of payout ,i could do with a survey to get me to the £50 mark” (Rose)

"Hi there, I reached $£ 50$ after about 3 years. Then there was a problem with my address and despite several e-mails, I never did receive the money, so I'm trying again!" (Heather)

"Hi there yes its taking me ages to get my first cheque to be honest, I have about 3 quid left to go I think. Its taken over a year I think and still have not reached it yet. Think I may unsubscribe after I get paid.” (Denise) 
Market research communities consist of a freelance workforce so many members’ purely desired financial rewards. Individuals' reliance on rewards seemed to be a main driver in their subsequent behaviour. This effect is likely to be initiated by the framing of change such as 'good for me' or 'bad for me' on the part of individuals. If the change was framed as positive for individuals they would be more likely to accept it and display positive online behaviour. In contrast if the change was framed as negative for individuals they would be more likely to display negative online behaviour which is damaging to firms by its influence on the whole online community. Members were found to threaten membership when payment for completing surveys was late, or if the payment threshold was taking too long to reach. Our findings point to negative behaviour online being dependent on individual factors such as reliance on rewards and knowledge of competitors' rates of pay. We therefore introduce individual factors into our model in Figure 1 as moderating variables. We were unable to investigate additional individual factors due to our direct qualitative research design but 'individual factors' is a broad heading so these factors can be included in subsequent research.

\section{Outcomes}

In respect to acceptance or non-acceptance of change and subsequent positive or negative behaviour online, the findings provide more detail than prior research.

\section{Positive Outcomes for the Firm}

Some members were not influenced by the change of strategy in so much as they did not modify their behaviour online. So for example, some members that supported the rules of the forum continued to do so and continued to attack those posting complaints or offensive comments. In light of these findings we include the following as positive responses to strategy change in the 
model (Figure 1): No Change in Behaviour, Rule Support and Attack of Complaining and Offensive Behaviour. The difficulty for the M.R.S. however, was that the negative effects were much more significant compared to these positive responses.

Negative Outcomes for the Firm

Negative effects were particularly pronounced such as the inclusion of posts advertising competitors. Over the three month analysis period several competitors were recommended through the forum after the strategy change. There was also a decrease in belongingness and social identity with M.R.S. as well as an increase in advertising competitors. There were just 2 complaints that points were not credited before the strategy change compared to 28 after, even though the points system remained exactly the same. A sense of membership of the community broke down, which is also evident by the increase in members feeling that the company is untrustworthy and only interested in money. This led community members posing negative comments that competitors were offering better pay while positive comments suggesting that M.R.S. is good or better for payment points decreased from 13 to 1 . In one post, 2 members of M.R.S. admitted joining a competitor after seeing previous posts, and 4 members emphasised the impressive earning potential from a competitor. Similarly positive comments that M.R.S. is good for points or better than competitors reduced from 13 before strategy change to zero after. Support within the online community for the firm was considerably reduced after the strategy change:

\section{RE: More surveys elsewhere}

"I love survey network and have made about $£ 120$ in 6 weeks. I use the manage log ins on my computer and so it will prepopulate a lot of the information for you so won't waste too much time when you get screened out” (Moira) 
"I joined survey network on 6 November after reading about it on here, but having tried to complete each daily survey and being screened out, and then doing 2 more surveys (as it says keep trying until you qualify!) I thought what a waste of time.

All I ever got was surveys from sites I am already a member of, inc M.R.S plc., for less money but not qualifying. Today (10 Nov) the site did not work at all, kept coming up all fuzzy/ page not displaying or surveys not coming up." (Elaine)

"I also joined survey network after reading about it here (thanks whoever). I agree that its a bit annoying going thru the 'no qualified' loop but I have earnt more there than any other site. Re their customer service - I put the wrong email address for my last paypal payment and (assuming that paypal would reject the request) emailed them to ask what I should do. I also got a very curt response along the lines of 'so what, what did I expect them to do?'. I replied explaining that the paypal account did not exist etc, they then replied that although their rules said that it was not their responsibility they would send another payment to the correct account - and have done so. Can't say fairer than that (except paypal must be making a fortune cos I can't be the only idiot putting in the wrong address)" (Helen)

These negative posts (detrimental to M.R.S.) were important because the whole online community were not only being influenced to join competitor panels by other members; but were also influenced by the potential of significant monetary imbursement, which is of significant importance within market research communities.

There is overwhelming evidence that members of M.R.S. showed concerns regarding external threats with members placing blame on the firm and its forum moderators. For instance, a single individual influenced and alarmed many other members by spreading rumours of financial instability within the firm (M.R.S.) following strategy change. In addition, high identifiers (such as Elaine) responded to this threat, supporting previous findings relating to the influence of such people (Doosje, Spears \& Ellemers, 2002). In this case the member had cashed their cheque previously and was trying to create sufficient uproar for M.R.S. to renounce and pay again; in 
affect they were using social influence against M.R.S. The overall effect of this rumour was that community members felt suspicious of the firm’s intentions:

\section{Mike - Uncleared cheque.}

"Today I received in the post a cheque that I paid in last week as unpaid and refer to drawer.

I was shocked. This cost me time and money trying to contact my bank to sort it out so have email M.R.S. asking for clarification.

And have added a £5 admin charge as the call to my bank is a 0871 number. Has anyone else banked a chq only to have it returned as bounced??” (Mark)

"That is quite shocking.

Keep us all posted on how you get on with M.R.S. and make sure you get your refund for the phone call you had to make (M.R.S. are a business after all so you are owed your refund).” (Elaine)

"Man alive that's more than shocking it's worrying as to the financial stability of M.R.S.

Are all of us who have grafted hard to make it to $£ 50$ going to get similarly stung!?!

M.R.S. over to you to comment............” (Mike)

Thus, our findings suggest that one community member influenced the opinions of others in a negative way. Social Influence Theory implies the directive power that one member can have, which can implicate a multitude of damaging effects to many (Asch, 1956; Clark, 1998; Forsyth, 2006; Moscovici, Lage \& Naffrechoux, 1969; Wood, Lundgren, Oullette, Busceme \& Blackstone, 1994).

Challenging social influence theory there was evidence to suggest defiance behaviour within the community. During the three months of analysis, one whole thread with over ten posts had to be removed from the website because 3 members were arguing so intensely. Though such evidence contradicts previous social influence findings where such defiance was not noted (Bagozzi \& 
Dholakia, 2002; Kelman, 1958), it is not an uncommon feature within forums (Dahlberg, 2001;

Kerr, Mortimer, Dickinson \& Waller, 2012; Kozinets, 1998). For example, the following thread highlights that for some individuals social influence does not explain their behaviour because they purposely created inflammatory comments to incite unnecessary disputes:

$\underline{R E: \text { Doctors Demand Smoking Ban in all Vehicles }}$

"If a private car contains children, there should be no smoking. I would like to think that most smokers would extend this courtesy to children without the need for police intervention. An adult can always refuse to travel with a driver that insists on smoking. A child may not have that option." (Daniel)

“SO WHAT'S IT GOT TO DO WITH YOU ANYWAY. LET SMOKERS BE YOU IDIOT” (Trevor)

There was also evidence of some aggressive behaviour within the community but also group acceptance when this behaviour was attacked:

$\underline{R E: ~ G o t ~} 51$ points

"I now have 55 points, are they carried over? Meaning say I get my cheque eventually for £50, the extra 5 points, will they be carried over to next time or taken away and started from scratch?” (Ray)

“DOH!

yes the 5 point's will be carried over.” (Paul)

"Please do not be rude to people who are asking genuine questions. We all try to be friendly and helpful on the forums even if people are asking questions that are available on FAQ's and have been mentioned many times before. Just remember some people may not be as computer savvy as yourself which is why they find it easier to ask questions that may be obvious to you but are difficult to find out for themselves." (Elaine)

"yes your right. I'm sorry if I offended anyone. I was just in a sarky mood yesterday. I'm ok now. and as for being savvy on computers, I just sort of muddle my way through." (Paul) 
Likewise, many members commented on previous posts in order to disagree. These comments however differ considerably to the inflammatory posts, because members still participated due to social influence. In light of these findings we include the following as negative responses to strategy change in the model (Figure 1): Competitor Advertisement, Inflammatory Behaviour, Offensive Behaviour and Complaints.

\section{INSERT FIGURE 1 NEAR HERE}

The model presented in Figure 1 builds on previous research that has highlighted the importance of social identity and group norm in online communities (Bagozzi \& Dholakia, 2002; Zhou, 2011) but also adds to previous models in a number of ways. First, the model recognises that individual factors act as moderating variables influencing the responses to strategy change. We suggest that individual factors such as knowledge of competitors and reliance on rewards predisposes the framing of a strategy change in a particular way and this framing impacts on the positive or negative behavioural responses. Some individuals chose to defy group behaviour at this point and posted negative comments which influenced others in the whole online community. The model also provides detail of behaviour in response to strategy change whereas previously research has only highlighted the reasons why participation in online forums occurs. Finally, the model is cyclical in nature because responses to strategy change impact further on online communities and set up new conditions for further social influence effects.

\section{Company response}

Shortly after the strategy change and the negative reactions within the online community forum outlined above, M.R.S. closed its online forum. Currently the firm’s freelance workforce have little opportunity to communicate. 


\section{Explanations for findings}

Members of the online community demonstrated high levels of congruence of opinion and interests with other members which is rooted in the members' aspirations to further themselves while also evolving their own role in the community (Dholakia et al., 2004). Theoretical explanations for this finding may also be found in the social psychology literature, including the theories of human needs. Niemiec and Ryan (2009) state that a “... proactive tendency to engage one's physical and social surroundings and to assimilate ambient values and cultural practices” is a natural tendency for a human nature (p. 133). This tendency is linked to human psychological need for social acceptance, relatedness and belongingness as described in a number or needbased theories of human behaviour.

For instance, a need for acceptance, affection and belongingness is classified as one of the higher-order needs by Maslow (1943) in his hierarchy of needs. Alderfer (1969) in his ERG (existence, relatedness and growth) theory also suggested that relatedness needs are important group of needs which include such elements as exchange of acceptance, confirmation and understanding. McClelland (1961) in his theory of needs proposed three main needs: those for achievement, those for power, and those for affiliation. The former two have an important role in explaining the main findings of the present study. The need for power, or the unconscious drive to impact other's behaviours, motivates people to influence and control others whereas the need for affiliation drives people to seek friendships based on mutual understanding and cooperation (Robbins, 2009). The findings suggest that forum members' behaviour was conditioned by members’ personal needs of feelings of belongingness, mutual understanding and power.

Previous research on conformity also aids understanding of members' negative behaviour. Research in the area of social influence has found peer group pressure to be particularly 
important (Bearden \& Rose, 1990) as well as the effects of providing a sound rationale to effect change (Cohen \& Golden, 1972). The findings point to knowledge and expertise as being particularly important for the increases in negative behaviour found in the study as well as the size of the online community (see Lascu, Bearden \& Rose, 1995). In the context of the current study, more knowledgeable experienced members of the M.R.S. community as well as its large size (130,000 members) are likely to have had an impact on members' tendency to highlight competitors’ employment opportunities and post inflammatory comments. In addition, certain members' knowledge and expertise was likely to influence others' tendency to follow their behavioural patterns. For example, M.R.S. members who posted negative messages are likely to have conveyed knowledge and expertise, such as detailed knowledge of competitors' rates of pay, which increased their social status within the network community and therefore the likelihood that others would follow them. This negative (negative for the firm) social identity effect was more prominent after the change of strategy presumably because the change heralded new conditions with which members of the community were unfamiliar. Some members were looking for more knowledge so that they could manoeuvre in this new landscape. This 'new' knowledge was provided by other members of the community in a negative way rather than by the firm itself. The firm did not communicate to its members on this issue. We acknowledge that this is a theoretical explanation for the negative behaviour found and needs to be followed up in future empirical studies.

From a wider management perspective the firm experienced difficult when setting up its online forum due to the decentralised nature of online communications. Decentralised communication patterns cannot be easily controlled so when the firm experienced the effects of negative behaviour in response to their strategy they reverted back to a centralised communication pattern 
with which they were more familiar and comfortable. i.e. they completely removed the online forum from the webpages. This centralised communication pattern is much more easily controlled.

\section{Conclusions}

The research provided important insights into the role that social influence plays after a strategy change within an online community. The findings confirm that social influence plays a central function in online communities. Strategy change prompted a change to both social influence constituents (social identity and group norm) as well as prompting an increase in negative responses and defiance behaviour. Despite members' heterogeneity and anonymity, individuals within the community were influenced both by group and individual behaviour. Social identity and group norm yielded significant effects to member participation; corroborating Social Influence Theory (Kelman, 1958). The online community exhibited powerful group behaviour; whereby members showed high levels of imitation and congruence of opinion. Yet after strategy change interactions altered and members identified less with other members of the community reducing group norm effects. They started to identify instead with a small number of members who posted negative comments and displayed knowledge of competitors' offerings.

Overall, the study confirms that social influence can exert a fundamental role within online communities. Yet, members' infatuation with monetary reward can lessen the resultant effects of social influence and facilitate both competitor advertisement and ultimately, a sense of mistrust, which could be detrimental to an organisation. At a higher level, the findings illustrate both positive (e.g. company loyalty) and negative effects (e.g. imitating negativity) that social influence can generate within computer mediated communications. 


\section{Implications for future research}

There is significant scope to investigate the possible effects of additional variables such as gender or age on social influence in responses to strategy change. Age related differences have been found, for example, in user reactions and technology usage behaviour in prior research (Venkatesh \& Morris, 2000). Including demographic variables in additional studies could aid further understanding.

As our research was conducted in a market research context, further exploration of other types of online community could help in supporting and generalising the model. In particular, research findings in firms that offer other types of reward, such as incentives for engagement, could be compared to the current model. Detailed case study research seems most appropriate as a starting point for such analytical generalisation to proceed.

Our data was coded purely on published comments and did not consider the personal (unpublished) beliefs of the members. Future research could address this limitation by widening the research to include other community members such as 'lurkers'. These are members of the online community that are effected by others' posts but do not comment themselves (Schlosser, 2005). It should be noted that company forums ordinarily tend to contain more negative feedback, as fully satisfied members rarely articulate their views. Therefore, widening the research to include all members of the community would pick up addition responses to strategy change. However, as noted above, it is difficult to obtain data on social influence by traditional quantitative means because social influence is inherently unconscious. Another difficulty in widening the research to include all members of online communities is that some members like to remain anonymous. Addressing these important barriers to research is required for statistical generalisation to occur. 


\section{Managerial implications}

The findings point to considerable advantages and disadvantages of setting up online communities and the impact they can have on the success of strategy change. One positive effect of setting up any online forum is the potential to gain much more information on the firm's stakeholders and their responses to strategy change. A main advantage for managers is that knowledge can be fed directly into management information systems and this is likely to be a key advantage to market oriented firms. Brand loyalty, engagement and advocacy for the firm can increase if forums are managed effectively. However, there are a number of caveats because the advantages need to be balanced with the risk of negative participation behaviour.

First, managers need to consider the resource implications of setting up online forums. Our findings point to the negative effects of competitor advertisement, offensive behaviour and complaints made by a few individuals on a large online community. Such findings suggest that managers need to organize continual moderation of forum posts and this is required $24 / 7$, but this is expensive. We suggest, that as a minimum, such intensive moderation of forums is required leading up to and shortly after a change in strategy. Staff, acting as moderators of online forums, also need to respond to posts in a timely fashion. They also need to respond in a way that is helpful to the community and in line with the firm's forum guidelines.

Managers also need to conduct regular reviews of the effectiveness and tangible benefits of any forum. In particular, changes to strategy need to monitored and discussed so that the impact on the whole community can be considered. Indeed, having no online forum is preferable to having one that spreads negative messages as was found here.

As community members demonstrated high levels of imitation and congruence of opinion, managers could aim to exploit such behaviour and organize the community website to highlight the more positive messages. For instance, M.R.S. attracted high numbers of welcome page views 
(90,731 average views per month) and forum page views (9,164 average views per month) yet a much lower hit rate within the testimonials section where purely positive comments are made regarding the organisation (1,377 average views per month). Consequently, such biased viewing suggests that negative influence will likely spread to a multitude of individuals, both those creating forums and to those that inadvertently read comments on websites. They should also facilitate greater emphasis on the testimonials and positioning these pages to an optimally situated location to encourage higher levels of readership; assisting greater levels of positive interaction.

In preparation for strategy change firms need to provide members of online communities with a considerable amount of clear explanatory literature. Community members need answers to major questions such as: what is the change, why is it happening, when will this occur, who will it effect and how will it happen. Online repercussions will occur during strategy change, but a detailed clarification of any changes in communication can help to decrease the amount of negative comments.

Additionally, false accusations should be succinctly corrected, before negative influence can spread. More timely moderation at M.R.S. plc. may have helped significantly in reducing negative influence such as that highlighted in flow diagram 1.

Numerous members within the community saw the moderators of the forum website as an outside and untrustworthy threat. Managers should therefore endeavour to decrease the gap between its online community members and forum moderators through a process of personalisation. Creating personal blogs, producing less formal posts and adding names could help to break down barriers between staff and forum members. Such variation is identifiable in today's society, where companies are diverging from traditional, impersonal communication to more individual and ad-hoc responses (Li \& Bernoff, 2008; Senecal \& Nantel, 2004; Valos, 
Ewing \& Powell, 2010; Wang, Baker, Wagner \& Wakefield, 2007). Firms can no longer afford to underestimate how significant online communities are in influencing company and brand perceptions (Kozinets et al., 2010). How strategy change is managed and communicated is also now under much more scrutiny than ever before within online communities. There are considerable benefits for firms if they set up and manage online forums effectively. Increased knowledge of the firm's stakeholders and their responses to strategy implementation and change can benefit market oriented firms, but the risks from negative social influence can easily outweigh the potential benefits.

\section{References}

Alderfer, C. P. (1969) An empirical test of a new theory of human needs, Organizational behavior and human performance, 4(2), 142-175.

Amabile, T. M. (1983) Brilliant but cruel: Perceptions of negative evaluators, Journal of Experimental Social Psychology, 19 (March), 146-56.

American Psychological Association (2002) Ethical principles of psychologist and code of conduct, American Psychologist, 57(12), 1060-1073.

Asch, S. E. (1956) Studies of independence and conformity: A minority of one against a unanimous majority, Psychological Monographs, 70, 1-70.

Ba, S. (2001) Establishing online trust through a community responsibility system, Decision Support Systems, 31, 323-336.

Bagozzi, R. P. and Dholakia, U. M. (2002) Intentional social action in virtual communities, Journal of Interactive Marketing, 16(2), 2-21.

Bearden, W. O. and Rose, R. L. (1990) Attention to social comparison information: An individual difference factor affecting consumer conformity, Journal of Consumer Research, 461471.

Brown, J., Broderick, A. and Lee, N. (2007) Word of mouth communication within online communities: Conceptualizing the online social network, Journal of Interactive Marketing, 21 (3), 2-20. 
Burnett, G. (2000). Information exchange in virtual communities: A typology

[Online]. Information Research, 5(4), Available from: informationr.net/ir/5-4/paper82.html [Accessed $5^{\text {th }}$ January 2011].

Christian, J., Bagozzi, R., Abrams, D. and Rosenthal, H. (2012) Social influence in newly formed groups: The roles of personal and social intentions, group norms, and social identity, Personality and Individual Differences, 52, 255-260.

Cialdini, R. B. and Goldstein, N. J. (2004) Social influence: Compliance and conformity, The Annual Review of Psychology, 55, 591-621.

Clark, R. D. (1998) Minority Influence, European Journal of Social Psychology, 28(5), 787796.

Click, A. and Petit, J. (2010) Social networking and Web 2.0 in information literacy, The International Information and Library Review, 42(2), 137-142.

Cohen, J. B., and Golden, E. (1972) Informational social influence and product evaluation, Journal of Applied Psychology, 56(1), 54-59.

Dahlberg, L. (2001) The internet and democratic discourse: exploring the prospects of online deliberative forums extending the public sphere, Information Communication and Society 4(4), 615-633.

de Valck, K., van Bruggen, G. H. and Wierenga, B. (2009) Virtual communities: A marketing perspective, Decision Support Systems, 47, 185-203.

Dellarocas, C. (2003) The digitization of word of mouth: Promises and challenges of online feedback mechanisms, Management Science, 49 (10), 1407-1424.

Dellarocas, C. (2004) Strategic manipulation of internet opinion forums: Implications for consumers, Management Science, 52(10), 1577-1593.

Dholakia, U. M., Bagozzi, R. P. and Pearo, L. K. (2004) A social influence model of consumer participation in network- and small-group-based virtual communities, Journal of Research in Marketing, 21, 241-263.

Doosje, B., Spears, R. and Ellemers, N. (2002) Social identity as both cause and effect: The development of group identification in response to anticipated and actual changes in the intergroup status hierarchy, British Journal of Social Psychology, 41, 57-76.

Ellemers, N., Kortekaas, P. and Ouwerkerk, J. W. (1999) Self-categorisation, commitment to the group and group self-esteem as related but distinct aspects of social identity, European Journal of Social Psychology, 29, 371-389.

Eysenbach, G. and Till, J.E. (2001) Ethical issues in qualitative research on Internet communities, British Medical Journal, 323, 1103-1105. 
Feldman, A. and Lu, X. (2007) Proceedings of the Workshop on Computational Approaches to Figurative Language. Rochester, NY: The Association for Computational Linguistics.

Flynn, F. and Chatman, J. (2003) What's the norm here? Social categorization as a basis for group norm development, Research on Managing Groups and Teams, 5, 135-160.

Flynn, L. R., Goldsmith, R. E. and Eastman, J. K. (1996) Opinion leaders and opinion seekers: Two new measurement scales, Journal of the Academy of Marketing Science, 24(2), 137-147.

Forgas, J. P. and Williams, K.D. (2001) Social influence: direct and indirect processes, Philadelphia, USA: Psychology Press.

Forsyth, D. R. (2006) Group dynamics, Belmon, CA: Thomas Wadsworth.

Haffaker, D. (2010) Dimensions of leadership and social influence in online communities, Human Communication Research, 3(4), 593-617.

Hamman, R. B. (1999) Computer networks linking communities: A study of the effects of computer network use upon pre-existing communities [Online], Available from:

http://cybersoc.blogs.com/mphil.html. [Accessed 23rd Jan 2011].

Huang, M., Cai, F., Tsang, A. S. L. and Zhou, N. (2011) Making your online voice loud: The critical role of WOM information, European Journal of Marketing, 45 (7), 1277-1297.

Hunton, J. E., Arnold, V. and Gibson, D. (2001) Collective user participation: a catalyst for group cohesion and perceived respect, International Journal of Accounting Information Systems, 2(1), 1-17.

Johnson, C. M. (2001) A survey of current research on online communities of practice, Journal of Internet and Higher Education, 4, 45-60.

Kane, G. C., Fichman, R. G., Gallaugher, J. and Glaser, J. (2009) Community relations 2.0., Harvard Business Review, 87(11), 45-50.

Kelman, H. C. (1958) Compliance, identification, and internalization: Three processes of attitude change, Journal of Conflict Resolution, 2(1), 51-60.

Kelman, H. C. (1961) Processes of opinion change, Public Opinion Quarterly, 25, 57-78.

Kelman, H. C. (1974) Further thoughts on the processes of compliance, identification, and internalization, 126-171 in Perspectives on Social Power, edited by James T. Tedeschi. Chicago: Aldine.

Kerr, G., Mortimer, K., Dickinson, S. and Waller, D. S. (2012) Buy, boycott or blog: Exploring online consumer power to share, discuss and distribute controversial advertising messages, European Journal of Marketing, 46(3), 387-405. 
Kim, J. W., Choi, J., Qualls, W. and Han, K. (2008) It takes a marketplace community to raise brand commitment: The role of online communities, Journal of Marketing Management, 24(3-4), 409-431

Kokich, C. (2009) Razorfish Digital Outlook Report. [Online], Available from:

http://digitaloutlook.razorfish.com/publication/?i=13617 [Accessed: $2^{\text {nd }}$ Feb 2011].

Kozinets, R. V. (1998) Ensouling consumption: A netnographic exploration of the meaning of boycotting behavior, Advances in Consumer Research, 25, 475-480.

Kozinets, R. V. (1999) E-tribalized marketing? The strategic implications of virtual communities of consumption, European Management Journal, 17 (3), 252-264.

Kozinets, R. V. (2002) The field behind the screen: Using netnography for marketing research in online communities, Journal of Marketing Research, 39, 61-72.

Kozinets, R. V., de Valck, K., Wojnicki, A. C. and Wilner, S. J. S. (2010) Networked narratives: Understanding word-of-mouth marketing in online communities, Journal of Marketing, 74 (2), 71-89.

Kreuz, R. J. and Caucci, G. M. (2007) Lexical influences on the perception of sarcasm, In: Workshop on Computational Approaches to Figurative Language: Annual meeting of the Human Language Technology Conference, April 2006. Rochester, New York: North American Chapter of the Association for Computational Linguistics.

Laing, A., Keeling, D. and Newholm, T. (2011) Virtual communities come of age: Parallel service, value, and propositions offered in communal online space, Journal of Marketing Management, 27(3-4), 291-315.

Lascu, D. N., Bearden, W. O. and Rose, R. L. (1995) Norm extremity and interpersonal influences on consumer conformity, Journal of Business Research, 32(3), 201-212.

Lee, M. K. O., Shi, N., Cheung, C. M. K., Lim, K. H. and Sia, C. L. (2011) Consumer's decision to shop online: The moderating role of positive informational social influence, Information and Management 48, 185-191.

Lee, N and Lings, I. (2008) Doing business research: A guide to theory and practice, Sage, 2008.

Li, H. and Bernoff, J. (2008) Groundswell: Winning in a world transformed by social technologies, Boston, USA: Harvard Business School Press.

McClelland, D. (1961) The Achieving Society, Van Nostrand.

Maslow, A. H. (1943) A theory of human motivation, Psychological review, 50(4), 370-396. 
Mitchell, M. L. and Jolley, J. M. (2007) Research design explained, Belmont, CA: Thomas Wadsworth.

Moscovici, S., Lage, E. and Naffrechoux, M. (1969) Influence of a consistent minority on the responses of a majority in a color perception task, Journal of Sociometry, 32(4), 365-380.

Niemiec, C. P. and Ryan, R. M. (2009) Autonomy, competence, and relatedness in the classroom Applying self-determination theory to educational practice, Theory and Research in Education, $7(2), 133-144$.

Nolan, J. M., Schultz, P. W., Cialdini, R. B., Goldstein, N. J. and Griskenvicius, V. (2008) Normative social influence is underdetected, Journal of Personality and Social Psychology, 34(7), 913-923.

Obholzer, A. and Roberts, V. Z. (1994) The unconscious at work, London: Routledge.

Postmes, T., Spears, R. and Lea, M. (2000) The formation of group norms in computer-mediated communication, Human Communication Research, 26(3), 341- 371.

Postmes, T., Spears, R., Lee, A. T. and Novak, R. J. (2005) Individuality and social influence in groups: Inductive and deductive routes to group identity, Journal of Personality and Social Psychology, 89(5), 747-763.

Preece, J., Maloney-Krichmar, D. and Abras, C. (2003) History of emergence of online communities. In Wellman, B. (Ed.), Encyclopaedia of Community, Berkshire Publishing Group, Sage.

Raven, B. H. (1993) The bases of power: origins and recent developments, Journal of Social Issues, 49(4), 227-251.

Robbins, S. P. (2009) Organizational Behavior: Pearson Education.

Schlosser, A. (2005) Posting versus lurking: Communicating in a multiple audience context, Journal of Consumer Research, 32 (2), 260-265.

Senecal, S. and Nantel, J. (2004) The influence of online product recommendation on consumers' online choices, Journal of Retailing, 80 (2), 159-169.

Shen, A. X. L., Cheung, C. M. K., Lee, M. K. O. and Chen, H. (2011) How social influence affects we-intention to use instant messaging: the moderating effect of usage experience, Information Systems Frontier, (13), 157-169.

Spaulding, T. J. (2010) How can virtual communities create value for business? Electronic Commerce Research and Applications, 9(1), 38-49.

Sridhar, S. and Srinivasan, R. (2012) Social influence effects in online product ratings, Journal of Marketing (76), 70-88. 
Valos, M. R., Ewing, M. T. and Powell, I. H. (2010) Practitioner prognostications on the future of online marketing, Journal of Marketing Management, 26(3-4), 361-376.

Venkatesh, V. and Morris, M. G. (2000) Why don't men ever stop to ask for directions? Gender, social influence, and their role in technology acceptance and usage behaviour, MIS Quarterly, 24(1),115-139.

Walther, J. B. (1996) Computer-mediated communication: Impersonal, interpersonal and hyperpersonal interaction, Communication Research, 23(1), 3-43.

Wang, L. C., Baker, J., Wagner, J. A. and Wakefield, K. (2007) Can a retail web site be social? Journal of Marketing, 71(3), 143-157.

Wang, S. and Lin, J. C. (2011) The effect of social influence on bloggers' usage intention, Online Information Review, 35(1), 50-65.

Whittaker, S., Isaacs, E., and O'Day, V. (1997) Widening the net: Workshop report on the theory and practice of physical and network communities, SIGCHI Bulletin, 29(3), 27-30.

Wood, W., Lundgren, S., Oullette, J. A., Busceme, S. and Blackstone, T. (1994) Minority influence: A meta-analytic review of social influence processes, Psychological Bulletin, 115, 323-345.

Xun, J. and Reynolds, J. (2010) Applying netnography to market research: The case of the online forum, Journal of Targeting, Measurement and Analysis for Marketing, 18(1), 17-31.

Yin, R. K. (2003) Case study research design and methods, Sage, Newbury Park, CA.

Zhou, T. (2011) Understanding online community user participation: a social influence perspective, Journal of Internet Research, 21(1), 67-81. 


\section{Exhibit 1}

"In early October we conducted a panel satisfaction survey asking for feedback on M.R.S. We found that 70\% of you feel you do not receive enough surveys from us; it was therefore no surprise that this was the top answer when we asked you "what one thing you would change". Patently this was something that needed addressing - and fast.

Our response has been to work hard at expanding our client base; an expanded client base means more surveys; and more surveys means those points will accumulate faster.

The market place in which we operate is highly competitive and in the past we have lost some projects based on our cost structure. Our client base expansion has obliged us to align our costs closer to those offered by competitors. So, what does that mean for you? It means an alteration to our incentives to fall in line with the market.

Incentive Changes

You will still receive $£ 1$ for the first 5 minutes of any survey you complete successfullythis will not change. The 5 minute increments thereafter will be set at lower variable incentives governed by the budget of the project we have won.

We anticipate having the increased volume of surveys on their way to you in the next few weeks." 


\section{Flow Diagram 1}




Table 1: Coded Responses in Forum Posts Before and After Change in Payment Strategy

\begin{tabular}{|c|c|c|c|c|c|c|c|c|c|c|c|c|c|c|c|}
\hline \multirow{2}{*}{$\begin{array}{l}\text { Coding Frame } \\
\text { Week }\end{array}$} & \multicolumn{7}{|c|}{ Before Change in Payment Strategy } & \multicolumn{7}{|c|}{ After Change in Payment Strategy } & \multirow{2}{*}{$\begin{array}{l}\text { OVERALL } \\
\text { TOTAL } \\
\end{array}$} \\
\hline & 1 & 2 & 3 & 4 & 5 & 6 & TOTAL & 7 & 8 & 9 & 10 & 11 & 12 & TOTAL & \\
\hline $\begin{array}{l}\text { Haven't received points/when will they be } \\
\text { credited }\end{array}$ & 0 & 0 & 0 & 0 & 1 & 0 & 1 & 7 & 3 & 2 & 7 & 7 & 2 & 28 & 29 \\
\hline $\begin{array}{l}\text { Haven't received a cheque/late cheque/when } \\
\text { will it be received }\end{array}$ & 2 & 3 & 4 & 3 & 1 & 1 & 14 & 2 & 1 & 3 & 0 & 0 & 1 & 7 & 21 \\
\hline Survey Error Complaint & 6 & 4 & 1 & 0 & 0 & 0 & 11 & 0 & 8 & 5 & 1 & 0 & 0 & 14 & 25 \\
\hline $\begin{array}{l}\text { Reaching } £ 50 \text { takes too long/MRS should } \\
\text { lower payment thresholds }\end{array}$ & 2 & 2 & 0 & 0 & 0 & 4 & 8 & 11 & 2 & 0 & 0 & 0 & 0 & 13 & 21 \\
\hline $\begin{array}{l}\text { MRS is good for points/better for points than } \\
\text { other survey sites }\end{array}$ & 4 & 0 & 0 & 6 & 2 & 1 & 13 & 0 & 0 & 0 & 0 & 0 & 0 & $\mathbf{0}$ & 13 \\
\hline $\begin{array}{l}\text { Screened out of survey complaint/Quality } \\
\text { Control is unfair }\end{array}$ & 0 & 1 & 0 & 0 & 3 & 8 & 12 & 1 & 4 & 4 & 4 & 3 & 1 & 17 & 29 \\
\hline $\begin{array}{l}\text { Cheque has now arrived/thanks for } \\
\text { cheque/points }\end{array}$ & 3 & 3 & 2 & 0 & 0 & 0 & 8 & 0 & 2 & 2 & 2 & 3 & 1 & 10 & 18 \\
\hline $\begin{array}{l}\text { How long does it take to get to } £ 50 \text { / When } \\
\text { are payment dates }\end{array}$ & 1 & 1 & 0 & 2 & 6 & 0 & 10 & 9 & 0 & 1 & 0 & 0 & 0 & 10 & 20 \\
\hline Query/ discussion of how the site works & 1 & 4 & 0 & 9 & 1 & 3 & 18 & 9 & 4 & 2 & 5 & 0 & 7 & 27 & 44 \\
\hline Survey invitations are biased & 3 & 0 & 0 & 0 & 0 & 0 & 3 & 0 & 0 & 1 & 0 & 0 & 1 & 2 & 5 \\
\hline Competitors are better/ better paid surveys & 0 & 0 & 1 & 0 & 0 & 0 & 1 & 4 & 1 & 1 & 1 & 0 & 0 & 7 & 8 \\
\hline MRS cheque could not be cashed & 0 & 0 & 5 & 0 & 0 & 0 & 5 & 0 & 0 & 0 & 0 & 0 & 0 & 0 & 5 \\
\hline Why haven't any/many surveys received & 1 & 0 & 3 & 0 & 5 & 1 & 10 & 4 & 0 & 3 & 1 & 0 & 0 & 8 & 18 \\
\hline Complaint that MRS use mutual points sites & 0 & 0 & 0 & 1 & 0 & 3 & 4 & 0 & 0 & 1 & 5 & 0 & 0 & 6 & 10 \\
\hline Incentives are poor & 0 & 0 & 0 & 0 & 0 & 0 & 0 & 7 & 1 & 0 & 0 & 0 & 0 & 8 & 8 \\
\hline $\begin{array}{l}\text { Don't like the use of cheques/prefer BACs } \\
\text { payments }\end{array}$ & 0 & 0 & 0 & 0 & 1 & 3 & 4 & 0 & 0 & 2 & 0 & 0 & 0 & 2 & 6 \\
\hline $\begin{array}{l}\text { MRS are untrustworthy/do not pay } \\
\text { members/only interested in money }\end{array}$ & 1 & 0 & 0 & 0 & 0 & 0 & 1 & 1 & 2 & 0 & 2 & 1 & 0 & 6 & 7 \\
\hline $\begin{array}{l}\text { Worried cheque won't arrive-entered address } \\
\text { wrong }\end{array}$ & 0 & 0 & 2 & 0 & 0 & 0 & 2 & 0 & 1 & 0 & 0 & 0 & 0 & 1 & 3 \\
\hline $\begin{array}{l}\text { Complaint that forum thread has been } \\
\text { deleted }\end{array}$ & 0 & 0 & 0 & 0 & 0 & 0 & $\mathbf{0}$ & 0 & 0 & 0 & 3 & 0 & 0 & 3 & 3 \\
\hline MRS has poor customer service & 0 & 0 & 0 & 0 & 0 & 0 & 0 & 0 & 1 & 1 & 1 & 0 & 0 & 3 & 3 \\
\hline Comments on MRS news blog/forum & 21 & 14 & 7 & 12 & 9 & 28 & 91 & 17 & 13 & 8 & 3 & 17 & 14 & 72 & 163 \\
\hline Comment/New post on members interests & 0 & 2 & 5 & 21 & 39 & 36 & 103 & 19 & 7 & 1 & 1 & 0 & 0 & 28 & 131 \\
\hline Other & 0 & 0 & 2 & 0 & 1 & 3 & 6 & 10 & 8 & 2 & 2 & 2 & 1 & 25 & 31 \\
\hline TOTAL & 45 & 34 & 32 & 54 & 69 & 91 & 325 & 101 & 58 & 39 & 38 & 33 & 28 & 297 & 622 \\
\hline Negative to MRS & 15 & 10 & 15 & 2 & 11 & 17 & 70 & 40 & 25 & 21 & 22 & 7 & 4 & 119 & 189 \\
\hline Positive to MRS & 7 & 3 & 3 & 6 & 3 & 4 & 26 & 4 & 6 & 3 & 5 & 4 & 0 & 22 & 48 \\
\hline Neutral & 23 & 21 & 14 & 46 & 55 & 70 & 229 & 57 & 27 & 15 & 11 & 22 & 24 & 156 & 385 \\
\hline TOTAL & 45 & 34 & 32 & 54 & 69 & 91 & 325 & 101 & 58 & 39 & 38 & 33 & 28 & 297 & 622 \\
\hline
\end{tabular}


Figure 1: A Social Influence Model of Online Community Responses to Strategy Change

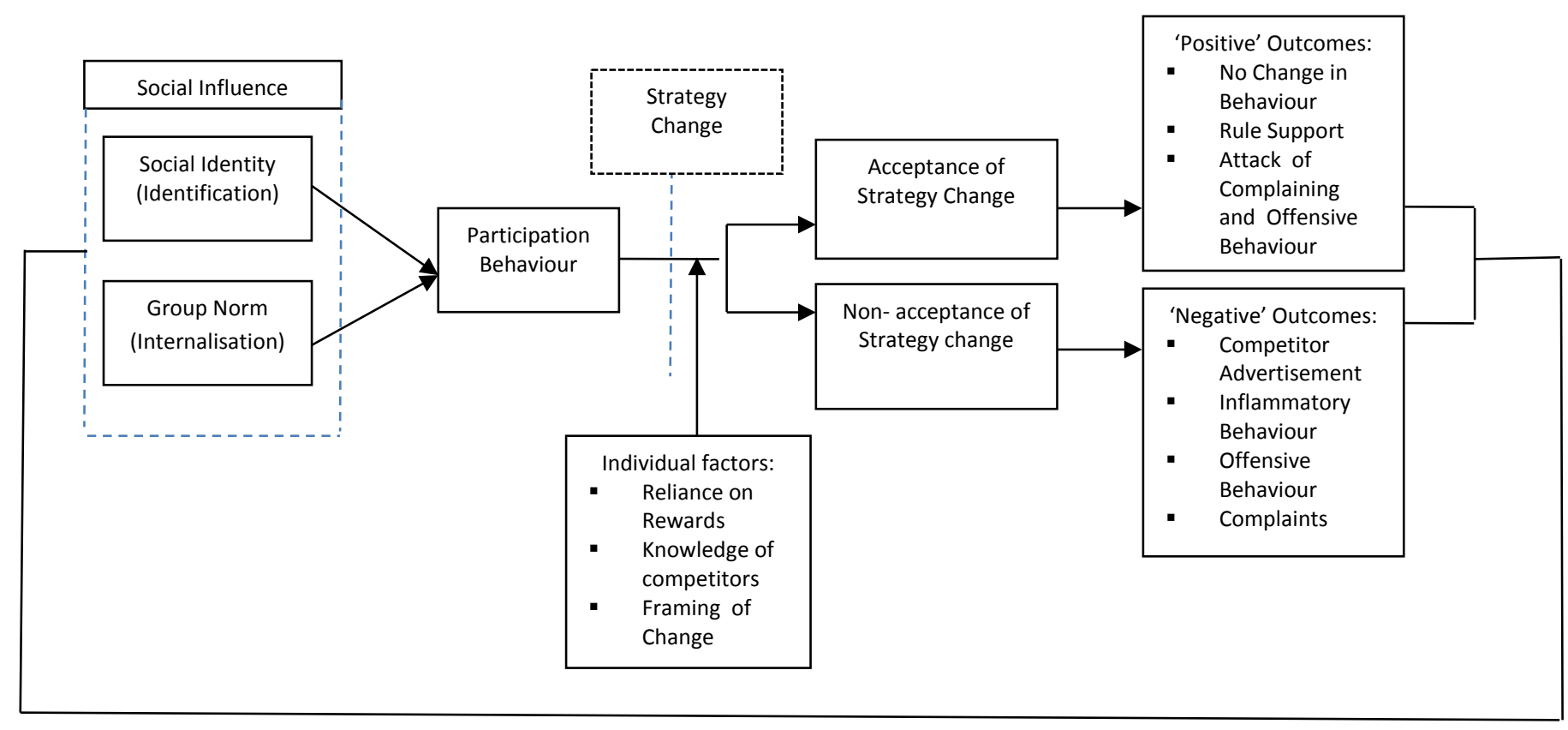

